\title{
VISUAL THINKING PROCESS AND EMOTIONS THROUGH EXPRESSIVE ART
}

\author{
Sabzali Musa Kahn'), Zahir Ahmad'), Maslinor Ismail2), \\ Nik Nairan Abdullah3), Rosmawati Ghazali4) \\ 1)Academy of Malay Studies, University of Malaya, Malaysia \\ 2)Department of Social and Preventive Medicine,University of Malaya, Malaysia \\ 3)Population Health \& Preventive Medicine, Universiti Teknologi MARA, Malaysia \\ 4)Faculty of Art and Design, Universiti Teknologi MARA, Malaysia
}

\begin{abstract}
Background: Drawing has a therapeutic function in the lives of people with special needs.These people need additional support for communication and learning.Researchers believed that drawing is an effective way for these people to show their self-esteem, emotions, social competence, and other hidden personalities. Art therapy teaches knowledge of visual art (drawing and painting). It is also known as expressive art because it assists in dealing with some emotions that are difficult for verbal communication. Furthermore, art therapy is beneficial for fine motor skill development. The aim of this study was to explore the use of expressive art in a group of autistic people.
\end{abstract}

Subjects and Method: This was a qualitative study. A series of art therapy workshop were conducted in University of Malaya in collaboration with Malaysian Rehabilitation Council, and Maybank Foundation. A number of 18 people aged 8-17 years old with autism from Malaysian Rehabilitation Council were invited to University of Malaya for the art therapy workshop. They consisted of Malays, Chinese, and Indians. These peoplehad some level of communication problems. Art therapy workshop was conducted twice a month for 6 month with each session lasted for 4 hours. Art template, art materials, and a list of activities were given to each participant. Before the session, the participants informed the researchers verbally the scope of art that they would be drawing. The researchers observed the thinking process and emotions of the participants through the art activities.

Results: Some of the art work was not related to what they have mentioned earlier. We found that art demonstrated their thought process. Drawing was more accurate in visualizing their thinking process rather than verbal communication. Besides, we detected a range of emotions illustrated from their final art work. Some of the emotions were psychological distress, happiness, and sadness.

Conclusion: Expressive artis useful for visualizing thinking process of autistic people.

Keywords: art therapy, autistic, visual thinking, emotions, expressive art

\section{Correspondence:}

Sabzali Musa Kahn. Academy of Malay Studies. University of Malaya, Malaysia. Email: sabzali@um.edu.my. 